ISSN: 0213-3563

https://doi.org/10.14201/azafea20202256

\title{
PRESENTACIÓN. FILOSOFÍA DEL DOLOR
}

\section{Introduction: Philosophy of Pain}

Iago RAmos e Indalecio GARCíA

Universidad de Salamanca

En el año 2015, un grupo de investigadores de la Facultad de Filosofía de Salamanca decidimos afrontar un concepto complicado: el dolor. La pregunta inicial fue tomando matices hasta que se conformó un proyecto de investigación que dio lugar a diferentes actividades, publicaciones, e intercambios de investigadores entre nuestro centro y universidades europeas y latinoamericanas. El acto principal de este proyecto fue la celebración en mayo 2018 del Congreso Internacional Philosophy of Pain / Filosofía del Dolor en Salamanca, que juntó a investigadores de más de nueve países. Este evento amplió las sinergias y las perspectivas de nuestro grupo.

Más allá de este proyecto, este número recoge variados trabajos sobre esta temática. Comprobamos cómo algunos problemas son recurrentes en los distintos trabajos presentados al número monográfico. Por un lado, percibimos un interés generalizado por diferenciar los conceptos de sufrimiento y de dolor, pues mientras este último se entiende como una realidad común a todo organismo con sistema nervioso, el primero parecería ser propio del ser humano (sería una valoración que este realiza respecto del dolor). Por otro lado, han sido tematizadas ciertas prácticas médicas y el modo como en ellas se entiende el dolor (señalando sobre todo el peligro de la deshumanización en los sistemas de salud actuales).

En este número se recogen contribuciones de investigadores que trabajan algunas de esas líneas de investigación sobre el dolor, que abarcan desde la problemática de la relación entre dolor y mente, pasando por el dolor en los animales, hasta la presencia del sufrimiento en la cultura. También contamos con una nota crítica y reseñas con las que se deja constancia de obras que también están dedicadas a la filosofía del dolor. En su artículo "Experiencia álgica y expresión doliente”, Xavier Escribano habla de la experiencia del mal y del dolor teniendo como fondo el arte; por su parte Francisco Mujica en “¿Pueden los animales sentir dolor?” analiza desde la fenomenología la posi- 
bilidad del dolor en los animales; Bernat Torres dedica su escrito "Paradoxes of Pain” a una audaz comparación de la postura platónica y la fenomenología en relación con el dolor; en "Thoughts on Pain”, Paolo Scolari nos da un panorama de la propuesta nietzscheana acerca del dolor; y Nieves Marín Cobos en su texto "Escribir desde el dolor" aborda desde la filosofía la obra Lo que no tiene nombre, de la poetisa Piedad Bonnet. Todos aportan visiones con las que se puede continuar debatiendo sobre un concepto que invita a diferentes aproximaciones. Finalmente, pueden encontrarse dentro del apartado monográfico de este número la nota crítica de Abraham Sapien-Córdoba, donde discute los argumentos de Collin Klein en What the Body Commands, texto clave para las teorías imperativistas del dolor; y la reseña del libro de Understanding Pain de Fernando Cervero, que no se ha sido tenido suficientemente en cuenta desde la filosofia, y que Sergio del Barrio recupera para este número y la discusión interdisciplinar.

Empezamos una investigación compartida en el 2015 con una pregunta sencilla, ¿qué es el dolor? Las respuestas no se agotan porque quedan muchas reflexiones pendientes, como las que se acogen en este monográfico. 